\title{
Exigências de Energia para Mantença de Bovinos Zebuínos Não-Castrados em Confinamento ${ }^{1}$
}

\author{
Mário Fonseca Paulino ${ }^{2}$, Carlos Augusto de Alencar Fontes ${ }^{3}$, André Mendes Jorge ${ }^{4}$, José \\ Carlos Pereira ${ }^{2}$, Paulo Gomes Júnior ${ }^{5}$
}

\begin{abstract}
RESUMO - As exigências líquidas de energia para mantença de bovinos de quatro raças zebuínas (Gir, Guzerá, Mocho-Tabapuã e Nelore) foram estimadas em experimento com 63 machos não-castrados, com idade média de 24 meses e peso inicial de $366 \mathrm{~kg}$ PV (16 das raças Gir, Guzerá e Mocho-Tabapuã e 15 da raça Nelore). Quinze animais, quatro das raças Gir, Guzerá e Mocho-Tabapuã e três da Nelore, foram abatidos no início do estudo e os demais, distribuídos em quatro grupos de 12 animais, sendo três animais de cada raça. Um grupo recebeu alimentação restrita, suprindo níveis de energia e proteína 15,0\% acima das exigências de mantença, segundo NRC (1984). Os animais dos três últimos grupos foram alimentados ad libitum, até atingirem peso vivo de abate de 405,450 e $500 \mathrm{~kg}$, respectivamente. A ração com $50,0 \%$ de concentrado na matéria seca foi fornecida individualmente a todos os animais. As exigências líquidas de energia para mantença foram determinadas, como estimativa do calor produzido em nível zero de ingestão de energia metabolizável, pela extrapolação da equação de regressão do log do calor produzido em função da ingestão de energia metabolizável. As exigências de energia líquida de mantença estimadas para animais das quatro raças, em conjunto, foram 60,4 kcal/kg PV P,75 $_{\bullet}$ dia, 21,85\% menores que o valor proposto pelo NRC (1996).
\end{abstract}

Palavras-chave: energia, mantença, raças zebuínas, confinamento

\section{Energy Requirements for Maintenance of Bulls from Zebu Breeds in Feedlot}

ABSTRACT - The net requirements of energy for the maintenance of bulls from four Zebu breeds (Gyr, Guzera, Mocho-Tabapuã and Nellore) were estimated with 63 bulls averaging 24 months of age and $366 \mathrm{~kg}$ initial LW and (15 Nellore and 16 from the Gyr, Guzera and Macho-Tapabuã). Fifteen animals, four Gyr, Guzera and Mocho-Tabapuã breed and three Nellore breed, were slaughtered at the beginning of the trial and the remaining were allotted to four groups of 12 animals, being three animals from each breed. One group was restricted fed, supplying levels of protein and energy 15,0\% over maintenance requirements, according to NRC (1984). The animals of the last three groups were full fed to reach the target live weight slaughter of 405, 450 and $500 \mathrm{~kg}$, respectively. A diet containing $50,0 \%$ concentrate as dry matter base and was fed individua lly to all animals. The net energy requirement for maintenance was determined as an estimation of heat production at zero metabolizable energy intake, by extrapolation of the regression equation of log of the heat production on the metabolizable energy intake. The estimated pooled net energy requirements for maintenance for the animals from the four breeds were $60.4 \mathrm{kcal} / \mathrm{kgLW}^{.75} \bullet$ day, $21.85 \%$, lower than the value proposed by NRC (1996).

Key Words: energy, maintenance, Zebu breeds, feedlot

\section{Introdução}

A importância dos requerimentos de energia para mantença na produção de gado de corte é evidenciada ao se considerar que 65 a $70 \%$ da energia metabolizável necessária para produção de carne são usados para satisfazer às necessidades de funções de mantença (FERRELL e JENKINS, 1985).

Para bovinos em crescimento e terminação, LOFGREEN e GARRETT (1968) separaram os requerimentos energéticos do animal em exigência de energia líquida para mantença (ELm) e para ganho (ELg). Segundo esses autores, os requerimentos de energia líquida para mantença equivalem à produção de calor do animal em jejum. Quando não há consumo de energia metabolizável (EM), o incremento calórico é nulo e os componentes de produção de calor são o metabolismo do jejum e o calor das atividades voluntárias do animal, correspondendo à exigência de mantença. A produção de calor de jejum é estimada por regressão, considerando-se vários níveis de alimentação e extrapolando-se a produção de calor para

\footnotetext{
1 Parte da Tese apresentada pelo primeiro autor à UFV para obtenção do título de "Doctor Scientiae". Trabalho realizado na UFV em colaboração com a EPAMIG e FAPEMIG.

2 Professor da UFV. Bolsista do CNPq.

3 Professor Titular - UENF - LZNA/CCTA, Campos, RJ.

${ }^{4}$ Pesquisador Científico da UNESP, Botucatu, SP.

5 Estudante de Mestrado da UFV.
} 
o nível zero de ingestão de energia metabolizável. O valor de $77 \mathrm{kcal} / \mathrm{kg} \mathrm{PCVZ}{ }^{0,75} / \mathrm{dia}$, encontrado pelos autores para machos castrados e novilhas, foi adotado pelo NATIONAL RESEARCH COUNCIL NRC (1996) para bovinos de corte.

O AGRICULTURAL RESEARCH COUNCIL ARC (1980)estimou, combase em estudos calorimétricos, o requerimento de ELm em $0,53 \mathrm{MJ} / \mathrm{kg}^{0,67} /$ dia para machos castrados e novilhas; para machos não-castrados recomendou acréscimo de $15 \%$.

Diferenças na musculatura, deposição de gordura ou produção de leite podem mudar a proporção de tecidos metabolicamente ativos e alterar a relação entre requerimentos de mantença e ganho de peso (KOONG et al., 1985; TAYLOR et al., 1986). Assim, o requerimento de mantença é variável, dependendo de peso, nível de produção, atividade, efeitos ambientais (FOX et al., 1988), raça, sexo, condição fisiológica e nível nutricional (KOONG et al., 1985). Para FERRELL e JENKINS (1985), os gastos de energia de mantença variam conforme idade, peso do corpo, raça ou espécie, sexo, estado fisiológico, estação do ano, temperatura e nutrição prévia, enquanto NOLLER e MOE (1995) enfatizam a influência do ambiente, raça, sexo e idade. Ainda, segundo TAYLOR e YOUNG (1968), os requerimentos de mantença podem variar de 20 a $30 \%$, devido a diferenças genéticas, o que parece ser de moderada a altamente herdável.

Variações nas exigências de mantença podem também ser explicadas, em parte, por variações em proporções de vários tecidos ou órgãos do corpo. Alguns estudos sugerem que a proteína do corpo, especialmente em órgãos viscerais, é muito mais ativa metabolicamente que o tecido adiposo e pode responder por diferenças em requerimentos de mantença por unidade de peso vivo metabólico $\left(\mathrm{PV}^{0,75}\right)$ entre diferentes tipos biológicos e estádios de desenvolvimento. A reciclagem protéica e o transporte de íons através das células representam mais de $50 \%$ do gasto total de energia para mantença (BALDWIN et al., 1980).

Para FERRELL et al. (1976), o total de energia gasto pelos órgãos internos, como coração, fígado, rins e intestinos, é maior que a energia gasta pelo tecido muscular. Segundo esses autores, os órgãos internos de novilhas de raças leiteiras (Jersey e Holandesa) são proporcionalmente maiores que os de novilhas de raças de corte (Hereford). Essas observações podem explicar, em parte, as observações de FERRELL e JENKINS (1984), em que os requerimentos de energia para mantença, por unidade de tamanho metabólico, foram maiores para vacas com alto potencial de produção de leite em relação aos de vacas com potencial moderado.

As recomendações de requerimentos de energia de COMMONWEALTH... - CSIRO (1990) baseiam-se na aceitação de variação no metabolismo de mantença (suporte). Como fontes de variação, admitem efeitos de raça, sexo, peso vivo, idade, atividade de pastejo e condições de clima. As recomendações para zebuínos são $20 \%$ menores que para taurinos.

Segundo o NRC (1984), as exigências de energia para mantença de raças zebuínas são menores que as encontradas, quando se utilizam as equações de LOFGREEN e GARRETT (1968), o que confirma os resultados de Mullick e Kehas, em 1952, citados por PATLE e MUDGAL (1975), que encontraram exigências de energia para zebuínos cerca de $20 \%$ menores que as de taurinos. ROGERSON (1971) observou que a produção média de calor de jejum em zebuínos foi inferior à dos animais taurinos $\left(80,4 \times 88,3 \mathrm{kcal} / \mathrm{kg}^{0,75}\right)$. Em ambas espécies, houve declínio semelhante na produção de calor com o avanço da idade do animal.

FOX et al.(1992) relataram que os animais zebuínos apresentam exigências de $89 \%$ em relação ao valor básico de $77 \mathrm{kcal} / \mathrm{kg}^{0,75} /$ dia usado pelo NRC (1984). NOLLER e MOE (1995) também afirmaram que raças de porte menor, como Bos indicus, podem requerer menos energia que o estimado pelo sistema de energia líquida.

FREITAS (1995) encontrou menor exigência de $\operatorname{ELm}\left(50,2 \mathrm{kcal} / \mathrm{kg}^{0,75} / \mathrm{dia}\right)$ para animais Nelore (NE) que para $\mathrm{F}_{1}$ Holandês - Nelore $(\mathrm{HN})$, Bimestiços (BM) e Bubalinos (BUF). Por outro lado, BOIN(1995) estimou em $69,8 \mathrm{kcal} / \mathrm{kg} \mathrm{PCVZ}{ }^{0,75} /$ dia a ELm de bovinos Nelore inteiros com 21 a 24 meses de idade.

Objetivou-se, com o presente estudo, estimar as exigências de energia para mantença de bovinos de quatro raças zebuínas (Gir, Guzerá, Mocho-Tabapuã e Nelore), não-castrados em confinamento.

\section{Material e Métodos}

O experimento foi realizado no Departamento de Zootecnia da Universidade Federal de Viçosa, em Viçosa-MG, no período de 14 de maio a 27 de outubro de 1994.

Foram utilizados 63 bovinos, sendo 16 Gir, 16 Guzerá, 16 Mocho Tabapuã e 15 Nelore, nãocastrados, com idade média de 24 meses e pesos vivos médios iniciais de 357,6;362,0;368,6; e 376,4 kg, respectivamente. Os animais permaneceram confina- 
dos, em baias individuais, com piso concretado e área de $30 \mathrm{~m}^{2}$, sendo $8 \mathrm{~m}^{2}$ cobertos com telhas de amianto, provida de comedouro e bebedouro de concreto.

Os animais de cada raça foram distribuídos em cinco lotes, uniformes quanto ao peso vivo e à condição corporal, os quais foram designados, aleatoriamente, aos tratamentos:

1 - Abate inicial ou referência $(\mathrm{AB})$;

2 - Alimentação restrita (AR);

3 - Alimentação ad libitum até o abate, a peso vivo de $405 \mathrm{~kg}$, equivalente a $90 \%$ do peso à maturidade das vacas da raça (AL1);

4 - Alimentação ad libitum até o abate, a peso vivo de $450 \mathrm{~kg}$, equivalente a $100 \%$ do peso à maturidade das vacas da raça (AL2); e

5 - Alimentação ad libitum até o abate, a peso vivo de $500 \mathrm{~kg}$, equivalente a $110 \%$ do peso à maturidade das vacas da raça (AL3).

No tratamento $A B$ foram alocados quinze animais, sendo quatro das raças Gir, Guzerá e MochoTabapuã e três animais da raça Nelore. Nos demais lotes foram alocados três animais de cada raça.

Após um período de adaptação de 60 dias, em que todos animais receberam o mesmo tratamento, os do lote $\mathrm{AB}$ foram abatidos, servindo como referência no estudo da composição corporal inicial dos animais. Os animais dos lotes AL1, AL2 e AL3 receberam, durante o período experimental, ração balanceada ad libitum, formulada segundo as normas do NRC (1984) para ganho diário de $1,1 \mathrm{~kg}$, atendendo, ao mesmo tempo, às exigências de proteína degradável no rúmen (PDR) e proteína não-degradável no rúmen (PNDR), segundo o ARC (1980). Os animais do lote AR

Tabela 1 - Composição da ração experimental (\% MS)

Table 1 - Composition of exprerimental diet (\% DM)

Ingrediente

Ingredient

$\%$

Feno de capim-braquiária

Brachiaria grass hay

Milho triturado

38,00

Ground corn

Farelo de soja

10,00

Soybean meal

Uréia

0,77

Urea

Mistura mineral ${ }^{1}$

Mineral premix ${ }^{1}$

${ }^{1}$ Fosfato bicálcico (dicalcium phosphate), 79,16\%; calcário calcítico (limestone), 7,9\%; cloreto de sódio (sodium chloride), 9,63\%; sulfato de zinco (zinc sulfate), $1,0 \%$; sulfato de cobre (cupper sulfate), $0,25 \%$; iodato de potássio (potassium iodate), $0,03 \%$; sulfato de cobalto (cobalt sulfate), $0,03 \%$. receberam a mesma ração, em quantidades limitadas, de forma a ingerirem quantidades de energia e proteína $15 \%$ acima das exigências de mantença.

A proporção volumoso: concentrado na ração foi, aproximadamente, de 1:1, na base da matéria seca (MS). A composição percentual da ração experimental é apresentada na Tabela 1 e os teores de matéria seca (MS), proteína bruta $(\mathrm{PB})$, energia metabolizável (EM) e macroelementos minerais dos ingredientes e da ração encontram-se na Tabela 2.

A ração foi fornecida uma vez ao dia, pela manhã. Para os lotes que receberam ração ad libitum, a quantidade de ração foi ajustada, de forma a manter as sobras entre 5 e $10 \%$ do ofertado. Tanto a quantidade de ração fornecida quanto as sobras foram registradas e amostras de ração e das sobras individuais foram coletadas, semanalmente, para análises químicas posteriores.

O período experimental não teve duração préestabelecida. Os animais foram abatidos assim que atingiram os pesos pré-estabelecidos de 405, 450 ou $500 \mathrm{~kg}$, correspondentes aos tratamentos AL1, AL2 e AL3, respectivamente. Para cada raça, à medida que era abatido um animal do grupo AL2, abatia-se também um animal do grupo AR, pareado ao início do experimento.

A cada 28 dias, todos animais eram pesados. À medida que um animal se aproximava do peso de abate pré-estabelecido, era pesado a intervalos menores, de forma a ser abatido com o peso previsto. Antes do abate, os animais foram submetidos a período de jejum de 16 horas. De cada animal abatido, pesaram-se e coletaram-se amostras representativas de sangue, rúmen-retículo, omaso, abomaso, intestino delgado, intestino grosso, mesentério, carne industrial, gordura interna, fígado, coração, rins, baço, pulmão, língua, couro, cauda, esôfago, traquéia e aparelho reprodutor. Para um animal de cada raça, foram pesadas, dissecadas e retiradas amostras de uma cabeça e um pé. As duas meia-carcaças foram pesadas no dia do abate e, posteriormente, resfriadas em câmara fria a $-5^{\circ} \mathrm{C}$, durante um período de 18 horas. Após esse período, foram retiradas da câmara fria, coletando-se uma amostra representativa da meiacarcaça esquerda, correspondendo à seção da $9^{\mathrm{a}}$ a $12^{\mathrm{a}}$ costela, segundo HANKINS e HOWE (1946), para posteriores dissecações, avaliações dos componentes físicos das carcaças e análises laboratoriais.

A composição física da carcaça (proporções de músculo, gordura e ossos) foi determinada por intermédio das equações propostas por HANKINS e HOWE (1946). 
PAULINO et al.

Tabela 2 - Teor médio de matéria seca (MS), proteína bruta (PB), energia metabolizável (EM), Ca, P, Mg, Na e K do feno, do concentrado e da ração experimental (\% MS)

Table 2 - Average content of dry matter (DM), crude protein (CP), metabolizable energy (ME), Ca, $P, M g, N a$ and $K$ in the hay, concentrate and experimental diet (\% DM)

\begin{tabular}{|c|c|c|c|c|c|c|c|c|}
\hline \multirow[t]{3}{*}{$\begin{array}{l}\text { Ingrediente } \\
\text { Ingredient }\end{array}$} & \multicolumn{8}{|c|}{$\begin{array}{c}\text { Componente } \\
\text { Component }\end{array}$} \\
\hline & MS & $\mathrm{EM}^{2}$ & PB & $\mathrm{Ca}$ & $\mathrm{P}$ & $\mathrm{Mg}$ & $\mathrm{Na}$ & $\mathrm{K}$ \\
\hline & $D M$ & $\begin{array}{c}M E \\
\mathrm{Mcal} / \mathrm{kg}\end{array}$ & $C P$ & & & & & \\
\hline Feno & 83,48 & - & 4,44 & 0,34 & 0,08 & 0,13 & 0,03 & 0,96 \\
\hline Hay & & & & & & & & \\
\hline Concentrado & 84,10 & - & 21,10 & 0,50 & 0,36 & 0,06 & 0,10 & 0,66 \\
\hline Concentrate & & & & & & & & \\
\hline Ração & 83,78 & 2,42 & 12,71 & 0,42 & 0,22 & 0,09 & 0,06 & 0,81 \\
\hline Diet & & & & & & & & \\
\hline
\end{tabular}

As análises químicas foram feitas, após secagem e pré-desengorduramento das amostras (KOCK e PRESTON, 1979), determinando-se os teores de proteína bruta, gordura, água, cinza e macroelementos minerais (Ca, P, Mg, Na e K), conforme SILVA (1990).

O peso do corpo vazio (PCVZ) dos animais foi determinado pela soma do peso da carcaça, do sangue, da cabeça, do couro, da cauda, dos pés, das vísceras e dos órgãos. A relação entre o peso do corpo vazio e o peso vivo (PV) dos animais referências (AB), de cada raça, foi utilizada para estimar o PCVZ inicial dos animais da mesma raça, que foram abatidos posteriormente.

O conteúdo corporal de energia foi determinado a partir dos conteúdos corporais de proteína e gordura e dos respectivos equivalentes calóricos, conforme a equação abaixo (ARC, 1980):

$$
\mathrm{CE}(\mathrm{Mcal})=5,6405 \mathrm{X}+9,3929 \mathrm{Y}
$$

em que

$\mathrm{CE}=$ conteúdo de energia;

$\mathrm{X}=$ proteína corporal $(\mathrm{kg})$; e

$\mathrm{Y}=$ gordura corporal $(\mathrm{kg})$.

Com o objetivo de se determinarem os coeficientes de digestibilidade da matéria seca e energia bruta da ração experimental, foi realizado um ensaio de digestibilidade, durante o período experimental, utilizando-se quatro animais (um de cada raça), que foram alojados em gaiolas de metabolismo e alimentados ad libitum. O ensaio teve duração de 21 dias, sendo 14 dias de adaptação e 7 dias de coleta, durante os quais se procedeu à medição do alimento consumido e da excreção total das fezes, com amostragem diária de alimento, fezes e sobras, conforme COELHO DA SILVA e LEÃO (1979). Os parâmetros do ensaio de digestibilidade são mostrados na Tabela 3.
As exigências de energia líquida para mantença (ELm) foram determinadas pela regressão do logarítmo da produção de calor, em função do consumo de energia metabolizável (EM), em kcal, por dia e unidade de peso metabólico, extrapolando-se a equação para o nível zero de consumo de EM, segundo o método descrito por LOFGREEN e GARRETT (1968). Face ao pequeno número de animais de cada raça envolvida, optou-se por uma avaliação conjunta dos dados, obtendo-se uma equação que representasse a exigência de mantença da média da população zebuína, partindo-se de um "pool" de animais representativos das quatro raças zebuínas de maior expressão numérica (Figura 1).

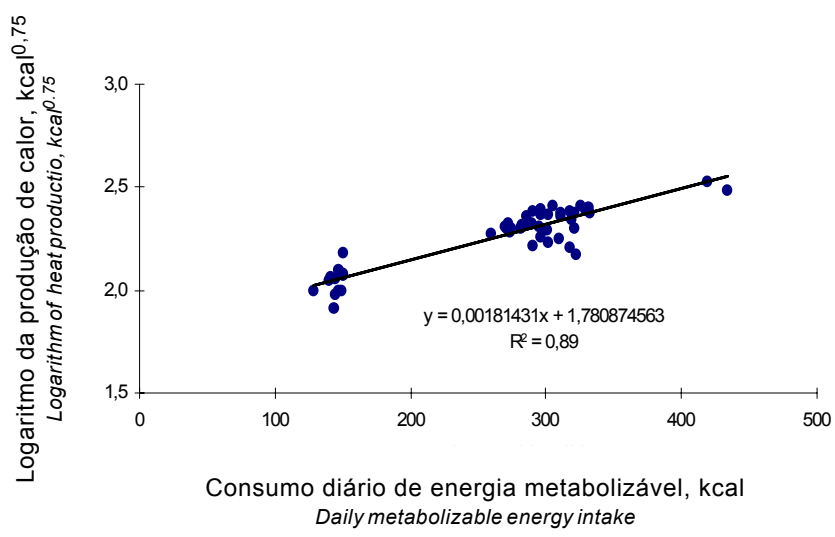

Figura 1 - Regressão do logaritmo de produção de calor em relação ao consumo de energia metabolizável diária (kcal).

Figure 1 - Regression of logarithm of heat production on the daily metabolizable energy intake. 
Rev. bras. zootec.

Tabela 3 - Dados do ensaio de digestibilidade da ração experimental

Table 3 - Data from the digestion assay of experimental diet Consumo ad libitum de matéria seca, \% PV 2,3 Ad libitum dry matter intake, \% $\mathrm{LW}$

Energia bruta, Mcal/kg MS

4,38

Gross energy, Mcal/kg DM

Coeficiente de digestibilidade da energia, \%

Coefficient of energy digestibility, $\%$

Energia digestível, Mcal/kg MS

2,95

Digestible energy, Mcal/kg DM

Energia metabolizável, Mcal/kg MS

Metabolizable energy, Mcal/kg DM

\section{Resultados e Discussão}

Pela regressão do logaritmo da produção de calor (PC), em função do consumo de energia metabolizável (CEM), em kcal por unidade de tamanho metabólico por dia, obteve-se a equação LOG PC $=1,780874563+$ 0,00181431 . CEM $; r^{2}=0,89$, que permitiu a determinação das exigências de energia para mantença para os bovinos das quatro raças zebuínas, em conjunto.

Extrapolando-se a equação para nível zero de consumo de energia metabolizável, obteve-se o valor de Elm de 60,4 kcal/kg PV $\mathrm{PV}^{0,75} / \mathrm{dia}$, para os animais das quatro raças zebuínas.

SALVADOR (1980) obteve, para novilhos azebuados, exigência de $56 \mathrm{kcal} / \mathrm{kg}^{0,75} / \mathrm{dia}$, que é $7,3 \%$ inferior ao encontrado no presente trabalho.

Trabalhando com animais da raça Nelore GONÇALVES (1988), PIRES et al. (1993) e FREITAS (1995) encontraram valores de 59,8; 34,2; e 50,2 kcal $/ \mathrm{kg}^{0,75} / \mathrm{dia}$, respectivamente. Por outro lado, BOIN (1995) encontrou valor de $69,8 \mathrm{kcal} / \mathrm{kg} \mathrm{PCVZ}{ }^{0,75} / \mathrm{dia}$. O valor de GONÇALVES (1988) foi o que mais se aproximou do valor obtido no presente trabalho, avaliando-se as quatro raças zebuínas em conjunto.

LOFGREEN e GARRETT (1968) observaram valor de $77 \mathrm{kcal} / \mathrm{kg} \mathrm{PV}^{0,75} / \mathrm{dia}$, para animais de raças européias; portanto, superior ao encontrado no presente trabalho. Os resultados obtidos no presente trabalho são coerentes com a literatura, que registra menores requerimentos para raças zebuínas em relação a raças de origem européia. ROGERSON (1971) também observou que a produção média de calor de jejum em bovinos zebuínos foi inferior à dos animais taurinos.

Considerando as afirmações de Mullick e Kehas em 1952, citados por PATLE e MUDGAL (1975) e CSIRO (1990), de que as exigências de mantença das raças zebuínas são $20 \%$ menores que as dos taurinos, e tomando o valor de $77 \mathrm{kcal} / \mathrm{kg} \mathrm{PV} 0,75 /$ dia como representativo das raças taurinas, o valor de $60,4 \mathrm{kcal} / \mathrm{PV}^{0,75}$ / dia encontrado no presente trabalho é bastante próximo do valor estimado de $61,6 \mathrm{kcal} / \mathrm{PV}^{0,75} / \mathrm{dia}$, ou seja, $80 \%$ de $77 \mathrm{kcal} / \mathrm{kg} \mathrm{PV}$ (0,75/dia; porém, é mais baixo que o valor de $68,5 \mathrm{kcal} / \mathrm{PV}^{0,75} /$ dia adotado por FOX et al.(1992), tomando por base que os animais zebuínos apresentam exigências de $89 \%$ em relação ao valor básico de $77 \mathrm{kcal} / \mathrm{PV}^{0,75} /$ dia, usado pelo NRC (1984).

A menor exigência de energia para mantença dos animais zebuínos pode estar associada à utilização mais eficiente da energia para mantença em relação ao taurinos ou a menor metabolismo basal.

As diferenças nas exigências de energia líquida para mantença entre grupos genéticos podem ser, em parte, explicadas por diferenças no tamanho de seus órgãos internos, que são maiores nos taurinos que nos zebuínos (FERRELL et al., 1976). JORGE (1993) verificou menor tamanho de órgãos internos de animais Nelore em relação a animais mestiços europeu-zebu. Por outro lado, os zebuínos apresentaram menores depósitos de gordura interna (PERON et al., 1993), que são metabolicamente mais ativos e têm influência nas exigências de mantença (THOMPSON et al., 1983).

\section{Conclusões}

Animais zebuínos apresentaram exigências de energia líquida para mantença cerca de $21,85 \%$ inferiores aos valores preconizados pelo NRC (1996).

\section{Referências Bibliográficas}

AGRICULTURAL RESEARCH COUNCIL - ARC. 1980. The nutrient requirements of ruminants livestock. London: Commonwealth Agricultural Bureaux. 351p.

BALDWIN, R. L., SMITH, N. E., TAYLOR, J. et al. 1980. Manipulating metabolic parameters to improve growth rate and milk secretion. J. Anim. Sci, 51(6):1416-1428.

BOIN, C. Alguns dados sobre exigências de energia e de proteína de zebuínos. In: SIMPÓSIO INTERNACIONAL SOBRE EXIGÊNCIAS NUTRICIONAIS DE RUMINANTES, 1995, Viçosa, MG. Anais... Viçosa, MG: CARD, 1995. p. 457-465. COELHO DA SILVA, J. F., LEÃO, M. I. 1979. Fundamentos de Nutrição dos Ruminantes. Piracicaba: Livroceres Ltda, 380p. COMMONWEALTH SCIENTIFIC AND INDUSTRIAL RESEARCH ORGANIZATION - CSIRO. 1990 Feeding standards for Australian livestock - ruminants. Victoria: Australia Agricultural Council. 266p.

FERRELL, C. L., JENKINS, T. G. 1985. Cow type and the nutritional environment: Nutritional aspects. J. Anim. Sci., 61(3):725-741.

FERRELL, C. L., JENKINS, T. G. 1984. Energy utilization by mature, nonpregnant, nonlactating cows of different types. J. Anim. Sci., 58(1):234-243.

FERRELL, C.L., GARRETT, W. N., HINMAN, N. etal.1976. Energy 
utilization by pregnant heifers. J. Anim. Sci., 42(4):937-950.

FOX, D. G., SNIFFEN, C. J., O'CONNOR, J. D.1988. Adjusting nutrient requirements of beef cattle for animal and environmental variations. J. Anim. Sci. 66(6):1475-1495.

FOX, D. G., SNIFFEN, C. J., O'CONNOR, J. D. et al. 1992. A net carbohydrate and protein system for evaluating cattle diets: III. Cattle requirements and diet adequacy. J. Anim. Sci., 70(11):3578-3596.

FREITAS, J. A. Composição corporal e exigência de energia e proteína de bovinos (zebuínos e mestiços) e bubalinos não castrados, em confinamento. Viçosa, MG:UFV, 1995.132p. Tese(Mestrado em Zootecnia) - Universidade Federal de Viçosa, 1995.

GONÇALVES, L.C. Digestibilidade, composição corporal, exigências nutricionais e características das carcaças de zebuínos, taurinos e bubalinos. Viçosa, MG: UFV, 1988. 238p. Tese (Doutorado em Zootecnia) - Universidade Federal de Viçosa, 1988.

HANKINS, O.G., HOWE, P.E. 1946. Estimation of the composition of beef carcasses and cuts. Washington, D.C., (Tech. Bulletin - USDA, 926).

JORGE, A. M. Ganho de peso, conversão alimentar e características da carcaça de bovinos e bubalinos. Viçosa, MG: UFV, 1993. 97p. Dissertação (Mestrado em Zootecnia) Universidade Federal de Viçosa, 1993.

KOCK, S.W., PRESTON, R.L. 1979. Estimation of bovine carcass composition by the urea dilution technique. J. Anim. Sci., 48(2):319-327.

KOONG, L.J., FERREL, C.L., NIENABER, J.A. 1985. Assessment of interrelationships among levels of intake and production, organ size and fasting heat production in growing animals. J. Nutr., 115(10):1383-1390.

LOFGREEN, G. P., GARRETT, W. N. 1968. A system for expressing net energy requeriments and feed values for growing and finishing beef cattle. J. Anim. Sci., 27(3):793-806.

NATIONAL RESEARCH COUNCIL - NRC. 1984. Nutrient requeriments of beef cattle. 6. ed. Washington, D. C. 90p.

NATIONAL RESEARCH COUNCIL - NRC. 1996. Nutrient requirements of beef cattle. 7.ed. Washington, D. C. $242 \mathrm{p}$.

NOLLER, C. H., MOE, P. W. Determination of NRC energy and protein requeriment for ruminants. In: PEREIRA, J. C. (Ed). SIMPÓSIO INTERNACIONAL SOBRE EXIGÊNCIAS NUTRICIONAIS DE RUMINANTES, 1995, Viçosa. Anais... Viçosa, MG: CARD, 1995, p. 53-76.
PATLE, B. R., MUDGAL, V. D. 1975. Maintenance requeriments for energy in crossbred cows. Brit. J. Nutr., 33(1):127-32.

PERON, A.J., FONTES, C.A.A., LANA, R.P. et al. 1993. Tamanho de órgãos internos e distribuição da gordura corporal, em novilhos de cinco grupos genéticos, submetidos a alimentação restrita e ad libitum. R. Soc. Bras. Zootec., 22(5):813-19.

PIRES, C.C., FONTES, C.A.A., GALVÃO, J.G. et al. 1993. Exigências nutricionais de bovinos de corte em acabamento. II. Exigências de energia para mantença e ganho de peso. $R$. Soc. Bras. Zootec., 22(1):121-32.

ROGERSON, A. 1971. Food intake and energy utilization by cattle. Nutr. Abst. Rev., 41(4):1359-1360.

SALVADOR, M. Exigências de energia e proteina para engorda de novilhos azebuados. Viçosa, MG: UFV, 1980. 70p. Dissertação (Mestrado em Zootecnia) - Universidade Federal de Viçosa, 1980.

SILVA, D.J. 1990. Análise de alimentos (Métodos químicos e biológicos). Viçosa, MG: UFV. 165p.

TAYLOR, St. C.S., THIESSEN, R.B., MURRAY, J. 1986. Interbred relationship of maintenance efficiency to milk yeld in cattle. Anim. Prod., 43(1):37-61.

TAYLOR, St. C.S., YOUNG, G.B. 1968. Equilibrium weight in relation to food intake and genotype in twin cattle. Anim. Prod., 10(3):393-412.

THOMPSON, W. R., MEISKE, J.C., GOODRICH, R. D. et al.1983. Influence of body composition on energy requeriment of beef cows during winter. J. Anim. Sci., 56(5):1241-1252.
Recebido em: 04/03/98

Aceito em: 04/12/98 